\title{
USING WASTE HIERARCHY CONCEPT FOR OPTIMIZING THE MANAGEMENT OF THE WASTE DISPOSAL AMOUNT AND IMPLICITLY OF THE POSSIBLE ECOLOGICAL RISK
}

\section{Georgeta Madalina Arama $^{1}$, Lidia Kim ${ }^{1}$}

1INCD-ECOIND 71-73 Drumul Podu Dambovitei, Sector 6, 060652, Bucharest, Romania, ecoind@incdecoind.ro

\begin{abstract}
The problem of applying the concept of waste hierarchy is presented considering the practical situation of packaging waste management to reduce the disposed waste amount and to control the possible ecological risk brought by them. The updated European and Romanian legislation is presented with emphasis on practical application at the organizational level so that the packaging waste recovery objectives, as they are shown in the legislative documents and national strategies, to be fulfilled by finding first the recovery possibilities and only afterwards the disposal ones for the environmental and human health protection.
\end{abstract}

Key words: disposal, packaging, recovery, waste,

\section{Introduction}

According to the European legislation, preventing the waste generation and performing an adequate management (recovery/disposal) is a strategy focusing on the prioritization of practical actions taking into account the sustainable development principles. This strategy is generic named "the waste hierarchy" and it aims to produce a maximum abatement of:

- $\quad$ the amounts of waste that should be disposed in final deposits;

- $\quad$ the detrimental effects for the environment and human health that the disposal might have in certain meteorological/climate and specific operations conditions of each deposit.

The difference between the practical real deposit operational conditions set by design and those that might arise along the time following operational phase might determine environmental detrimental effects in the surrounding deposit site area. Consequently in the closure, post-closure and cleaning phases the monitoring should be realized according to the legal applicable regulations to assure that possible environmental impacts/risks are determined and kept under control with adequate timely measures. Prediction of possible ecological risks of industrial final disposed waste supports a good management decision by identifying the hazards and their manifestation conditions assessing the possible negative consequences for the environment and human health that might appear all along the active life of those deposits but also in the next periods namely in the closure/post-closure phases. This prediction should be done taking into account the knowledge of the updated legal requirements in relation to the technical and environmental monitoring of the deposit and its surrounding areas under the influence of possible incidental/accidental deposit emissions. In practice, the 
general concept of managing waste supposes to realize three categories of activities (Fig.1)

A. collecting activities,

B. transport activities,

C. treatment (processing) activities

\section{A. Collecting activities}

B. Transport activities

\section{Treatment activities}

C1-Recovery activities: Operations that are referring to the recovery included in Annex 3 Law 211/2011

C2-Disposal activities: Operations that are referring to the disposal activities included in Annex 2 Law 211/2011

Figure 1 - Categories of activities involved in waste management

Legislation that regulates each category of activities tries to better organize the way in which waste should be managed so that more recovery than disposal to be achieved. Category "C" of activities, namely that of treatment (processing) of waste can be divided in two big classes: $\mathrm{C} 1$. activities referring to recovery and $\mathrm{C} 2$ activities referring to the disposal. The operations included in the two classes $\mathrm{C} 1$ and $\mathrm{C} 2$ are defined in a disjunctive way in the sense that, operations that are performed within $\mathrm{C} 1$ class, recovery activities, that are presented in a non-exhaustive list in Annex II of the Directive 98/2008/EEC [1] and Annex 3 of the Law nr. 211/2011 [2], cannot be part simultaneously of the operations group performed within C2 class, disposal activities, and that are presented within a non-exhaustive list in Annex I of the Directive 98/2008/EEC [1] and the Annex 2 at the Law nr. 211/2011 [2].

Applying the waste hierarchy as a strategy for waste management activities involves as first step the search of possibilities (the best possibilities - the best available techniques) for the recovery and only afterwards of those for the disposal. The performed operations that are also included in the class of recovery activities are considered (pre)processes and they have the purpose to transform waste so they become useful either in the same organization where they have been produced /generated or in other organizations. The waste management means waste recovery and waste disposal. The definition given by the current legislation for the recovery is presented in the Annex 1 of the Law nr. 211/2011 (point 24) [2] and states "The recovery means any operations that have as result transforming/preparing waste to serve a useful purpose through the replacement of other materials in the same organization or in economy in general"

In relation with the case study that will be presented we should mention that within the frame of recovery a special place is assigned to the re-cycling that is defined in Annex 1 to the Law nr. 211/2011 (pct 18) [2] where it is stated: "The re-cycling means any 
recovery operation through which the waste have been transformed in products, materials or substances that can fulfill the initial function or for other purposes/functions. That includes the retreatment / reprocessing of organic material, but does not include the energetic recovery and the conversion intended for the use of material as fuel or for the filling operation".

By definition in European and Romanian legislation for waste the recovery by recycling is clear different from the energy recovery.

\section{Experimental}

Next is presented the case of a Romanian organization at the 2016 level that should solve a problem of waste management related exactly to the necessity of applying the concept of waste hierarchy in the light of present European (Directive 2004/12/CE [3], Directive 94/62/CE [4]) and Romanian legislation (Law 249/2015 [5]). The steps that should be taken in order to solve such a case, are presented next in order to find out the optimum course of action. The organization uses in its activity a series of substances classified and labeled by the producer as dangerous having a certain concentration and one or more warning/risk phrases related to dangerous properties. The Romanian organization buys these substances from outside the country. They are packed in a primary packing container of 100 liters made of plastic material with a metal frame and put into secondary and tertiary packing wooden boxes. After one single use, those plastic containers become packing waste containing hazardous chemical residues. Between the organization that commercializes them from outside Romania and the Romanian organization that uses them there is no agreement of deposit - system type. According to this type of agreement, the buyer, the Romanian organization, when buys the packed products can pay a sum of money that can be returned when the packing containers are sent back to the producer/trading company.In those conditions, because there is not such agreement in place and because the plastic packing container is not of the re-use category as is defined in Annex 1 of Law 249/2015 at the point 1) g. [5] it becomes packing waste at the consumer, i.e. in Romania. According to art.16 (9) from the Law 249/2015 [ 5 ] "the economic operators holding the waste packing code 15.01 - as stated in Annex 2 of the H.G. nr. 856/2002 regarding waste management records and the approval of the waste list including the dangerous waste resulted from their commercial, industrial or productive activities, with next updates - has the obligation after selectively collected them to recover them by itself or contract an authorized economic operator that can process them for recycling or waste energy recovery by incineration purposes.

Law nr. 211/2011 [2] that transposes the requirements of Directive1999/31/CE [6] of the Council of 26 April 1999 at the art. 8 states:

"(1) The waste producers and holders as juridical person are obliged to categorize/classify each type of waste generated from their own activity according to the waste list from art 7 aln. (1).

(2) When a certain type of waste can be found according to the waste list from art.7 (1) under two different codes depending on the possible presence of some dangerous characteristics - the codes marked with asterisk, the classification of waste as nondangerous ones is realized by the producers and holders of such waste only on the basis of origin, tests and analytical reports/results and other relevant documents. 
(3) The ANPM (Romanian acronym for National Agency of Environmental Protection) through its reference laboratory, analyzes the uncertainty cases with reference to the characterization and categorization of waste.

(4) The waste producers and holders, as juridical person, are obliged to have a characterization of the generated dangerous waste from their own activity that can be considered dangerous by their origin or composition, in order to determine the possibility of waste mixing, treatment and disposal.

(5) The waste producers and holders, public defense authorities, national safety and administrative public order organizations have the legal obligation to make classification using the codes from the Annex nr. 2 of the H.G. nr. 856/2002 Governmental Decision [7]. This Decision is referring to keeping the waste records of each type of waste generated from their own activity including the dangerous ones according to the waste list, based on specific current regulation for waste management"

Consequently the organization from our case study has the legal obligation to manage the packing waste that contains the chemical dangerous residues and to classify them under the code $15.01 .10^{*}$ according to the origin. Any packing containers containing dangerous residues become dangerous waste. Applying waste hierarchy strategy the Romanian organization should find first recovery possibilities and only afterwards, if this recovery is not possible the organization should look for the disposal ways.

\section{Results and Discussion}

To adequately mange the waste according to the waste hierarchy the organization should undertake the following steps:

1. Declare first the packing plastic containers as waste (according to the law the waste is defined as mobile property that the producer/holder should, has the intention or obligation to discard it).

2. Categorize and register the waste (plastic containers of $100 \mathrm{~L}$ with dangerous residues) under the code $15.01 .10^{*}$ after its origin, finding it on the national list from Annex 1 of the Governmental Decision 856/2002 [7]

3. Dissemble the waste in metal, wood and plastic parts.

4. Contact an authorized economic operator that can process plastic waste material through a melting process but this economic agent process only nondangerous plastic waste. So the organization can see if the waste can be preprocessed so that can be re-classified as non-dangerous

In those conditions, the endeavor of managing this type of waste is a complex one and will be presented next. In order to determine the dangerousness of the waste and to (pre)treat it for re-classification as non-dangerous waste according to Order 95/2005 [8] and Law 211/2011 with updates [2], it is recommended to verify if the packing waste, respectively if the wall of the container contains dangerous substances that can impart dangerous properties apart from those declared by the producers of that type of plastic material.

Taking into account that, to be used as a plastic container packaging product for a certain type of substance, the container material should be chemically inert to that substance at the declared concentration and at the storage temperature, before testing 
the container material wall - which in our specific case is Polyethylene of High Density - for dangerous substances it is recommended a easier endeavor. Romanian organization can require from the organization that produces/commercializes the dangerous substances packed in those plastic containers a document that can acknowledge the fact that the container wall material is chemically inert to the contained substances at the concentration and storage conditions (temperature) can be asked to be sent. This type of document should be made available to the client organization even if there is not an usual request. This Endeavour represents a sort of supplementary declaration of responsibility from the part of the organization that put on the market those products but this way they can actively be involved at the common effort of recovery of plastic materials. The recycling objectives EU legislation for plastics are set at $22.5 \%$ in weight at least, taking into account only the plastic recycled material. The specialty catalogs for materials and relativities of different types of substances at different concentrations and at different temperatures usually indicate the chemical inertia of the materials for different uses (packing, pipes, pipe joints elements etc). Also, the Romanian organization that uses those containers may require to the producer a counseling regarding possibilities for decontamination/washing of containers. All this information should normally exist at the producers and, in the spirit of free access to the information for the consumer it can be released without infringement of any proprietary information confidential agreement. This way, both parts can prove their proactive environmental protective attitude trying to minimize the amount of final disposed dangerous waste and the possible environmental risk brought by them.

The endeavor has the purpose to make a common effort both from the producer part and from the consumer part to regulate an issue that is of general concern reducing at the minimum the dangerous waste transfer in the spirit of Basel Convention on the Control of Transboundary Movements of Hazardous Wastes and Their Disposal - art.4 (2) (d) - and of the Regulation CE 1013/2006 of the European Parliament and Council from 14 of June 2006 [9] concerning the trans-boundary transport of the dangerous waste. Depending on the received answer, the organization can try to re-classify the waste with the purpose of applying the waste hierarchy being in two possible situations presented next. If the plastic container wall is chemically inert at the content of the container according to the declaration of producer organization that put on the market those products packed in the plastic containers, then, the Romanian organization shall try to provide a washing/decontamination technology. A number of trials should be made with reference to establish the optimum (wash)/(decontamination) process keeping the washing water separately from each step if the process will require multiple steps: Container substance $A(1,2, . . n$ washing waters samples), Container substances B $(1,2, . . \mathrm{m}$ washing water samples),.....etc, One can see if the obtained values are relevant for setting a washing/decontamination procedure. This procedure will allow to draw conclusions concerning the dangerousness of the waste based on the final found $A, B, C$,..etc. trace amounts of dangerous substances. For instance, A might be a substance used by the organization and commercially called Bronopol. It is classified under the CAS number 52-51-7 corresponding to 2 Brome -2 nitro-1,3 propandiole. Substance B might be a substance used by the organization production process and commercially called Prequel 200 classified under the CAS number 68784 -12-3 with EC number 272-221-2 corresponding to (C15-C210)2 Alkenil Succinic Anhidride etc. The found amounts will be compared to the legal stated amounts based on which the container can be declared as non-dangerous waste according to the H.G. 856/2002 and L.211/2011 legal requirements. The washing/decontamination process will set a 
number of optimum "k" washing/decontamination phases depending on the substance (mixture of substances) and their solubility in the used solvent or water assuring the smallest technological and economical achieving content of dangerous substances in the waste according to the law enforcement. The decontamination/washing waters will be tested for the content of dangerous substances in a specialized laboratory. In practice, when the decontamination/washing process will be in place, the resulted waters from the washing/decontamination process having dangerous substances will be treated together with the process waste waters from the productive plants that normally contain those substances that result from the technological production process and they have already assigned treatment technologies for reaching the environmental permit requirements. If the plastic container wall has a certain reactivity, i.e. it is not totally inert and there is doubt that a slightly adsorption/absorption upon the container wall might exists, then, one can recommend - in a very cautious proenvironmental protection attitude - a wall material testing with a specialized organization/laboratory for thermoplastic/elastomers tests. They can perform tests by immersing the plastic wall samples in concentrated substances/mixture of substances at the stated label concentrations for a relevant standard testing period of time, at the storage temperature to make relevant spectra of existing substances. Usually in the literature referring to the plastic recycling by melting in MSDS (Material Safety Data Sheets ) there are recommendations for dangerous fumes that might be emitted during the process of melting and different other substances/fragments of substances that can be finally found in the melted material depending on the used plastic and its initial production ingredients/additives. This kind of information is also taking into consideration as necessary knowledge for re-classifying the waste in order to recycle it through a melting process. Generally speaking, the companies that produce for example pipes and joint elements to assembly those pipes that are made of plastic materials, offer guides for chemical resistance to different substances and conditions. [10] Usually, they use three classes of chemical resistance a) class of high chemical resistance - materials that are completely inert when used with certain chemical substances at specified levels of concentration/temperature; b) class of limited chemical resistance - materials that are partial attacked by certain chemical substances at the specified levels of concentration/temperature and c) class without chemical resistance - materials severely attacked by certain chemical substances at specified levels of concentration /temperature. It is obvious that a material attacked by the substances in prescribed conditions cannot be used as packing containers for those substances. However, we can mention that the presence within the plastic material of different kind of components such as additives or the presence of trace amount of impurities in the substance contained in container may increase the susceptibility of a chemical attack on the container plastic wall but again, the range of conditions of usual storage should dictate the final judgments and interpretation. Through the recommended test it can be verified the presence of the suspected substances that might impart the dangerous properties of the plastic packing waste intended to be melt according to the present law. Having the quantitative analytical results thus obtained one can compute according to the existing European methodological recommendations, the amount of dangerous substances that impart dangerous properties of each type and compare those amounts with the current legal corresponding limits (H.G. 856/2002 [7], H.G. 937/2010 [11]) finding out if the plastic container thus cleaned can be classified as non-dangerous waste after origin, documentation and composition. 


\section{Conclusions:}

Finally one should conclude that the organization performing the presented successive steps based on the legal requirements will be able to demonstrate that the washing/decontamination process allows the reclassification of the plastic packing waste as non-dangerous packing waste. Thus the waste can be recycled trough a melting process fulfilling this way the national recycle objectives mentioned in the current legislation.

\section{Acknowledgements:}

This paper was made under the Contract 38N/2016, Add. Act. 1/2016 - PN 16-25.02.09

\section{References}

[1] D. 2008/98/EC (2008), DIRECTIVE 2008/98/EC OF THE EUROPEAN PARLIAMENT AND OF THE COUNCIL of 19 November 2008 on waste and repealing certain Directives Official Journal L. 312, of 22.112008, p.3-30. http://eur-lex.europa.eur/

[2] L.211 (2011), Law nr. 211 of 15 November 2011 regarding the waste regime Official Monitor nr. 837 of 25 November 2011. Legis Data Base

[3] D. 2004/12/EC (2004), Directive 2004/12/EC of the European Parliament and of the Council of 11 February 2004 amending Directive 94/62/EC on packaging and packaging waste Statement by the Council, the Commission and the European Parliament. http://eurlex.europa.eur/

[4] D. 94/62/EC (1994), European Parliament and Council Directive 94/62/EC of 20 December 1994 on packaging and packaging waste. http://eur-lex.europa.eur/

[5] L. 249 (2015), Law nr. 249 of 28 October 2015 (updated) regarding the way of managing the packaging and packaging wastes. Official Monitor nr. 809 of 30 October 2015.Legis Data Base

[6] D. 1999/31/EC (1999), Council Directive 1999/31/EC of 26 April 1999 on the landfill of waste Official Journal L 182 , 16/07/1999 P. 0001 - 0019. http://eur-lex.europa.eur/

[7] H.G. 856 (2002), Governmental Decision nr. 856 of 16 August 2002 regarding the waste management records and for the approval of the list of waste, including those of dangerous waste ( dangerous waste are marked with an asterisk*) Official Monitor nr. 659 of 5 September 2002. Legis Data Base

[8] 0. 95 (2005), Order nr. 95 of 12 February 2005 regarding stating acceptance criteria and preliminary procedures of waste disposal and national list of waste accepted in each waste deposit class (Official Monitor nr. 1994 or 9 March 2005). Legis Data Base

[9] R. 1013 (2006), REGULATION (EC) No 1013/2006 OF THE EUROPEAN PARLIAMENT AND OF THE COUNCIL of 14 June 2006 on shipments of waste. http://eur-lex.europa.eur/

[10] www.ipexinc.com - Catalogs for Plastic Chemical Resistance

[11] H.G. 937 (2010), Governmental Decision nr. 937of September 1-st 2010 regarding the classification, packaging and labeling when putting on the market of dangerous preparation. Official Monitor nr. 690 of 14 October 2010.Legis Data Base 